\title{
CANDIDAL COLONIZATION AND PALATAL DENTURE BASE ADAPTATION IN RELATION TO DENTURE BASE MATERIALS AND THEIR PROCESSING TECHNIQUES
}

\author{
Hala Mohamed Abd El Hameed*
}

\begin{abstract}
Purpose: The purpose of this research was to compare between the effect of denture base materials and their processing techniques on palatal denture base adaptation and candidal colonization.

Materials and methods: Thirty identical denture bases was constructed by silicon mold which was made from a educational edentulous maxillary cast . Thirty maxillary stone casts were obtained by pouring hard dental stone in the previous silicon mold. Sheets of wax with $2 \mathrm{~mm}$ thickness, each were adapted to their corresponding stone casts then divided equally into three groups. Group I: Ten maxillary heat cured acrylic resin denture bases processed by long cycle hot water bath curing technique. Group II: ten maxillary acrylic resin denture bases processed by microwave energy. Group III: Ten maxillary monomer free thermoplastic resin denture bases processed by sabelix injecting system. Palatal denture base adaptation and candidal colonization were evaluated. The data was recorded and statistically analyzed.
\end{abstract}

Results: The results of this study showed that statistically there was significant difference in palatal denture base adaptation between the tested groups as $(\mathrm{p}=0.024)$. The least mean gap (stone thickness) at the posterior palatal seal area was found in Acrifast denture base resin (G III) followed by GI. The least mean numbers of candidal colonies for the three groups was found in Acrifast denture base resin (G III) followed by GI . Statistically there was highly significant difference of candidal colonization between the three tested groups as $(\mathrm{p}<0.001)$.

Conclusion: Based on the limits of this study, it could be concluded that injectable monomer free thermoplastic resin denture base material is preferred to minimize candidal colonization, enhance the accuracy of denture base adaptation and increase the opportunity for obtaining successful complete denture.

* Assistant Professor of Prosthodontics, Faculty of Dentistry, Suez Canal University 
Since 1937 acrylic resin has been considered the material of choice for construction of complete or partial dentures. It has many advantages including good esthetic properties, low solubility, adequate strength, facility of repair and it can be fabricated by easy technical procedures ${ }^{1}$

The retention and stability of the denture bases are enhanced by close adaptation of the denture base to the palate to maintain thin film thickness of the saliva between the base and the tissue. Attachment of artificial tooth and equal distribution of the force applied by the muscles are important roles of denture bases which in turn maintains the tissue without lesion and facilities the chewing procedure. So, adaptation of denture base to the bearing area is an important factor affecting the success of the resultant complete dentures. ${ }^{2}$

Conventional heat processing is the most popular method of processing denture base acrylic, although the linear dimensional shrinkage is about $0.3 \%$ greater than the chemically cured acrylics, the heat curing system has adequate accuracy and low laboratory coast . On the other hand processing acrylic resin denture base materials by conventional techniques leading to change in its dimensions during different steps resulting in reduction in adaptation of the denture base.$^{3}$

Most dental material researches have focused upon developing PMMA materials to increase its strength, decrease levels of residual methacrylate monomer after processing, improve dimensional stability, increase radiopacity and improve resistance to candidal infiltration. The modifications of poly methyl methacrylate material such as the pour type, high impact strength resin ,reinforced denture base resin, rapid heat polymerized resin ,light activated denture base resin ,dual denture base resin, microwave polymerized resin and thermoplastic acrylic resin have been introduced ${ }^{4}$

With the advancement and continuous progress in science and technology, many investigations were designed to improve mechanical and physical properties of acrylic resin either by addition of modifiers or the modification of its processing techniques. These advances led to the introduction of modified polymethylmethacrylate (PMMA) injectable thermoplastic material and injection molding technique .Using the molding - injection system has great advantages as the material is available in cartridges so avoiding any mixing errors, with maintenance of high mechanical resistance ${ }^{5}$.

Thermoplastic resins have been used in dentistry for fifty years. The technology is based on plasticizing the material using only thermal processing in the absence of any chemical reaction. The possibility of injecting the plasticized resin into a mold has opened a new perspective to full denture and removable partial denture technology. ${ }^{6}$

Thermoplastic resins have several advantages including, long-term performance, stability, resistance to deformation, resistance to wear, excellent tolerance, resistance to solvents, absence or low quantity of residual monomer and lack of porosity, all of which are very important characteristics for removable dentures, presenting a high degree of flexibility and resistance. ${ }^{7}$

Acrylic resin formulated for microwave polymerization have been introduced as alternative to water bath and light cured resins. The physical properties of microwave strips were compared to that a conventional water bath. It was found that the important physical characteristics of microwave cured resin are the same as resin cured in conventional water bath but microwave energy reduced curing time, easy in manipulation and cleanliness ${ }^{8}$.

The human oral cavity harbors multiple different microorganisms, one of them is Candida albicans. Candida albicans is the most significant member which cause oral candidiosis ? 
Colonization of C. albicans to different denture base materials had been studied. The different researches indicate that there are many factors affecting colonization of $\mathrm{C}$. albicans including: hydrophobic nature of the material surface, free energy and water sorption property of the denture base material. ${ }^{10}$

So, this research is designed to study the effect of denture base materials and their processing techniques on palatal denture base adaptation and candidal colonization.

\section{MATERIAL AND METHODS}

Thirty identical denture bases were constructed as follow: A silicon mold was made from a educational edentulous maxillary cast. Thirty maxillary stone casts were obtained by pouring hard dental stone in the previous silicon mold.

Sheets of wax with $2 \mathrm{~mm}$ thickness, each was adapted to its corresponding stone casts. The thirty waxed up denture bases were divided equally into three groups.

Group I: Ten maxillary heat cured acrylic resin denture bases processed by long cycle water bath curing technique.

Group II: Ten maxillary acrylic resin denture bases processed by microwave energy.

Group III: Ten maxillary monomer free thermoplastic resin denture bases processed by sabelix injecting system.

\section{Processing denture bases with microwave energy:}

The waxed up denture bases were flasked using dental investment stone type IV in fiber reinforced plastic flask (Acron MC microwavable flask, U.S.A.). Wax elimination was done by applying the flask in microwave oven (Clatronic,D47906Kempen/German) with 500 watt for $1 \mathrm{~min}$ to soften the wax. The flask was placed in the microwave oven in the center of the turn - table for $8 \mathrm{~min}$ at 500watt power to dry up the investment . ${ }^{8}$

After final packing of the dough acrylic resin the two halves of the flask held together by tightening the three bolts securely. The flask was placed in the microwave oven for $15 \mathrm{~min}$ at low power 90 watt followed by $2 \mathrm{~min}$ at high power 500 watt The flask was leaved to bench cool, deflasked then any flashes were removed. The denture bases were trimmed, finished and polished ( fig. 1A\& 1B)

\section{Processing the denture bases thermally using in- jecting molding system}

The waxed - up denture base was placed in the lower half of the flask which was filled with Plaster. Separating medium was painted and wax sprue 5 $\mathrm{mm}$ in diameter was added to ensure sufficient space for the introduction of the plasticized material, the channels are inserted into the waxed denture base at the distal end of the denture base.

The flask was closed and a new mixture of gypsum was poured and vibrated through the hole of the flask until the upper half was filled. After 20 minutes the flask was immersed in boiling water for 5 minutes to soften the denture base wax .

The sabilex injection machine was turned on at temperature $280^{\circ} \mathrm{C}$ for 25 minutes. The cartridge was chosen, painted with insulator and placed in the area of the heating unit located near the top of the injection machine (Sabilex, Microinjection machine, Argentina). The flask was locked in position in the upper part of the machine using the bracket system. The process was then activated. This automatically completed the cycle till the filled flask can be removed. ${ }^{6}$

The filled flask was leaved to cool down to room temperature before deflasking. Channel sprues were removed with a metal disc. The denture bases were trimmed, finished and polished ( fig. 1C\& 1D) 


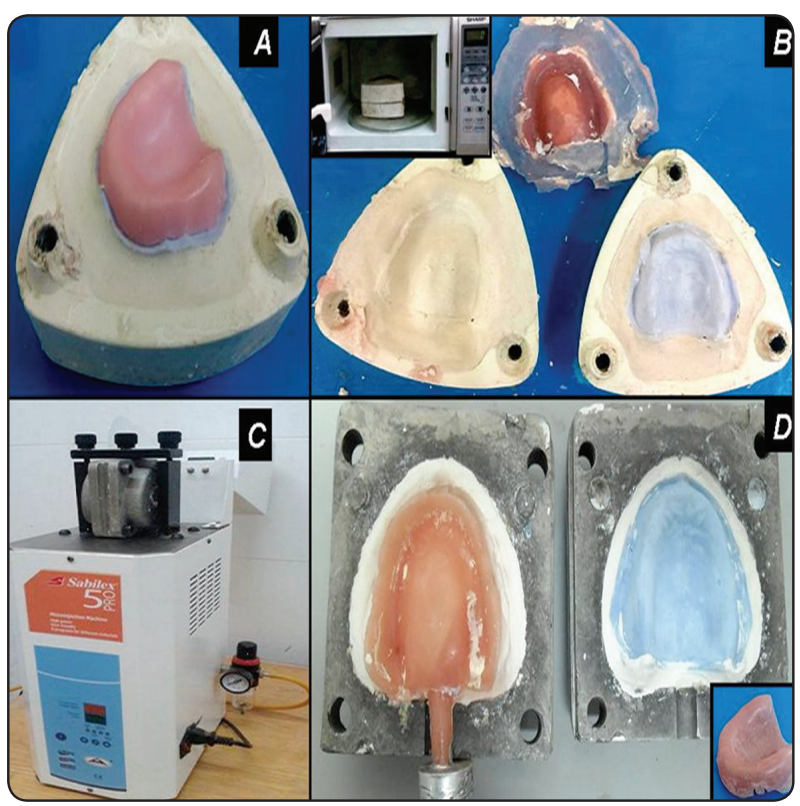

Fig. (1) A\& B Processing denture bases with microwave energy C\& D processing denture bases with sabilex injecting system

\section{Measuring the palatal adaptation}

The previously mentioned maxillary denture bases of the three materials were prepared. A standard maxillary cast with blocked undercuts was made from epoxy material and three marks were done at the most posterior palatal seal area of the cast .First mark at median palatine raphea and other two marks at distance $7 \mathrm{~mm}$ right and left to the first mark. The thickness of the cast at posterior palatal seal area was measured at these three marks by inserting the cast between the two extremities of the digital caliper (Electronic digital caliper, sakkary tool China with $0.01 \mathrm{~mm}$ accuracy) at each mark till the ledge present at the lower extremity of the caliper to obtain first measure

Silicon occlusal rim was fabricated by injecting silicon material in horseshoes shaped mold, and then the silicon rim was sealed parallel to mounting plate of the articulator.

The epoxy maxillary cast was clamped by surveying table .Separating medium was applied on the fitting surface of denture base. The soft stone type IV put in the fitting surface of denture base then the denture base with the stone were applied on the cast .

The articulator plate with the silicon occlusal rim was placed on the denture base with the occlusal rim facing down word settled on the denture base. The whole assembly inserted on the plate of a hydraulic machine parallel to it.

The platform of the hydraulic cylinder was pressed on the mounting plate till ten bar, maintaining the pressure for ten min for setting of stone under denture base.

Each denture base was removed from the cast. The thickness of the cast with stone was measured by inserting the cast with stone between the two extremities of the digital caliper at each mark till the ledge present at the lower extremity to obtain second measurement.

The thickness of stone was calculated by subtracting the measure of the cast from the second measurement ( fig. 2A, 2B \& 2C). The results were recorded, tabulated and statistically analyzed

\section{Measuring of candida albicans colonization:}

\section{I-Preparation the denture base specimens:}

Specimens of $10 \mathrm{~mm} \times 10 \mathrm{~mm}$ were cut from anterior half of the denture bases including incisive papilla and a part of rugae area. All specimens were washed and stored in sterile distilled water.

\section{II-Culture preparation:}

Candida albicans was incubated in $10 \mathrm{ml}$ of Sabouraud's broth at $37^{\circ} \mathrm{C}$ for $24 \mathrm{hrs}$. Then this was added to $90 \mathrm{ml}$ of Sabouraud's broth and further incubated at $37^{\circ} \mathrm{C}$ for $24 \mathrm{hrs}$ to attain a stationary phase (Incubated medium). The control medium was prepared from sabouraud's broth without candidal incubation.

The incubated medium was divided into three sterile Petri dishes, ten specimens from each group 
were added in each of Petri dish containing the incubated medium (incubated group). The control medium was dispensed in three Petri dish, five specimens were added in each petri dish containing controlled medium (control group). Then all specimens were incubated at $37^{\circ} \mathrm{C}$ for $48 \mathrm{hrs}$. After completion of the incubation, all specimens were washed in sterile phosphate buffered saline, fixed using sterile methyl alcohol for 1 min after which the alcohol will be drained. Staining was done using Gram's staining technique .

Specimens were then washed in water and the stained smear was permitted to air dry. A drop of cedar-wood oil was applied over the specimen (on a glass slide) and observed under oil immersion lens (40x) of light microscope. Microscopically, yeast cells are dark purple and show characteristic budding (fig. 2D\& 2E) . The number of colonies of candida albicans were counted in each field (incubated group) then the mean for each sample was calculated. The number of candidal colonies of all samples were tabulated and statistically analyzed. ${ }^{11}$

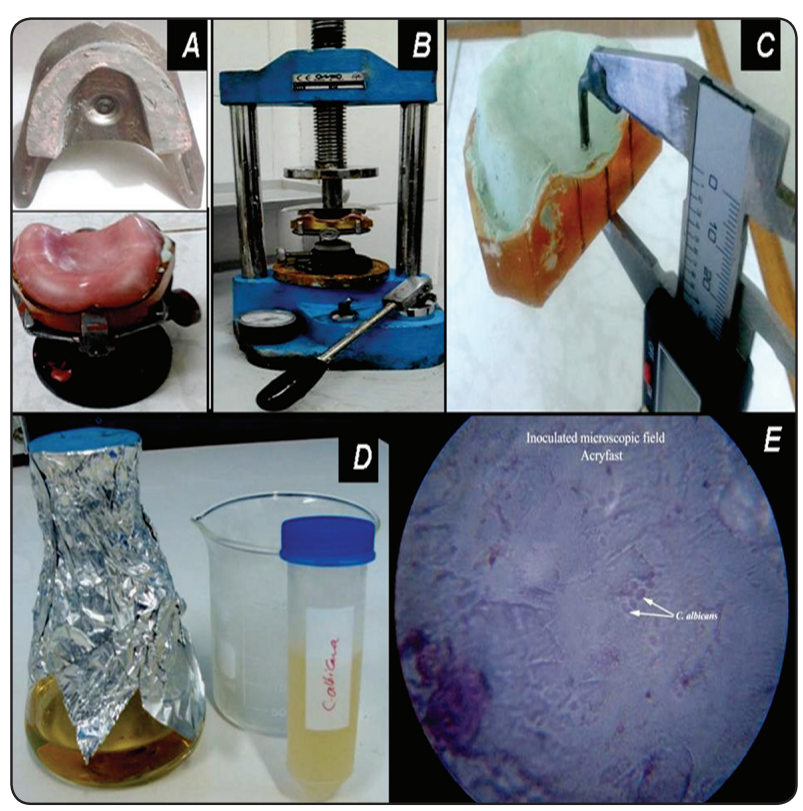

Fig. 2A, 2B \& 2C Measuring of palatal adaptation using electronic digital caliper 2D \& 2E Measurement of Candida albicans colonization

\section{RESULTS}

The obtained data were calculated and statistically analyzed by Fisher LSD method as means, stander deviation(SD) and p-value which is considered significant at $\mathrm{p} \leq 0.05$ and highly significant at $\mathrm{p} \leq 0.001$.

From table (1), fig.(3A) the least mean gap (stone thickness) at the posterior palatal seal area for the three groups was found in Acrifast denture base resin (G III) followed by GI (heat cured denture base resin) then GII (microwave cured denture base resin) with statistically significant difference in palatal denture base adaptation between the tested groups $(\mathrm{p}=0.024)$.

TABLE (1) The mean gap at the posterior palatal seal for three group

\begin{tabular}{|c|c|c|c|}
\hline Group & Mean \pm SD & F & p-value \\
\hline $\begin{array}{c}\text { Heat cured denture } \\
\text { base resin (GI) }\end{array}$ & $0.745 \pm 0.201$ & & \\
\hline $\begin{array}{c}\text { Microwave cured } \\
\text { denture base resin } \\
\text { (GII) }\end{array}$ & $1.004 \pm 0.416$ & 4.320 & $0.024^{*}$ \\
\cline { 1 - 2 } $\begin{array}{c}\text { Acrifast denture } \\
\text { base(GIII) }\end{array}$ & $0.606 \pm 0.297$ & & \\
\hline
\end{tabular}

From table (2) comparison between the three groups for palatal denture bases adaptation by using all pairwise multiple comparison procedures (Fisher LSD Method). Statistically there was highly significant difference between GII and GIII in favor to acrifast denture base $(\mathrm{p}=0.009)$, also significant difference between GI and G II in favor to heat cured denture base $(\mathrm{p}=0.040)$ and finally there was no significant difference between G I and G III $(\mathrm{p}=0.522)$ 


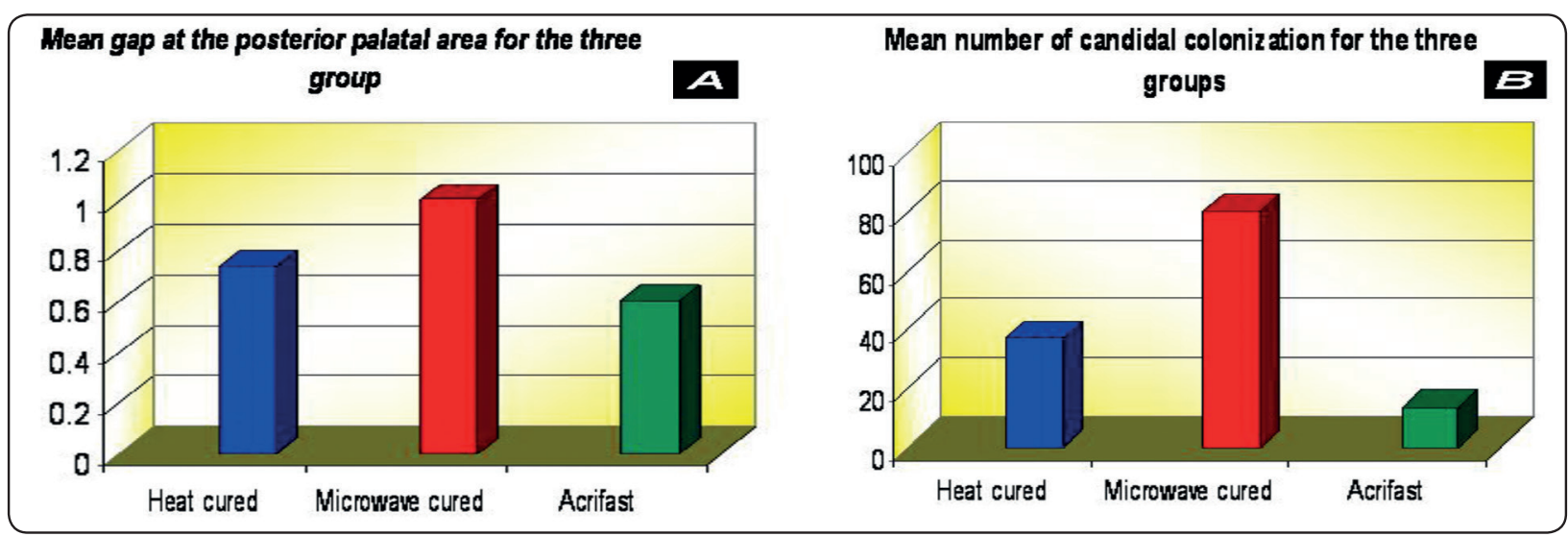

Fig. (3) A \& B Bar charts showing Comparison between the three groups in palatal adaptation \& candidal colonization

TABLE (2) Comparison between the three groups for palatal denture bases adaptation.

\begin{tabular}{|c|c|c|c|}
\hline Comparison & $\mathrm{D}$ & LSD & p-value \\
\hline $\begin{array}{l}\text { Microwave cured denture base } \\
\text { and acrifast denture base }\end{array}$ & 0.398 & 0.291 & $0.009 * *$ \\
\hline $\begin{array}{l}\text { Microwave cured denture base } \\
\text { and heat cured denture base }\end{array}$ & 0.306 & 0.291 & $0.040^{*}$ \\
\hline $\begin{array}{l}\text { Heat cured denture base and } \\
\text { acrifast denture base }\end{array}$ & 0.0920 & 0.291 & 0.522 \\
\hline
\end{tabular}

From table (3), fig.(3B) the least mean numbers of candidal colonies for the three groups was found in Acrifast denture base resin (G III) followed by GI then GII . Statistically there was highly significant difference of candidal colonization between the three tested groups as $(\mathrm{p}<0.001)$.

TABLE (3) The mean numbers of candidal colonies for three group

\begin{tabular}{|c|c|c|c|}
\hline Group & Mean \pm SD & F & p-value \\
\hline $\begin{array}{c}\text { Heat cured denture base } \\
\text { resin (GI) }\end{array}$ & $37.1 \pm 21.76$ & & \\
\cline { 1 - 2 } $\begin{array}{c}\text { Microwave cured denture } \\
\text { base resin (GII) }\end{array}$ & $80.1 \pm 54.01$ & 9.79 & $0.001^{* *}$ \\
\hline $\begin{array}{c}\text { Acrifast denture } \\
\text { base(GIII) }\end{array}$ & $13.6 \pm 9.73$ & & \\
\hline
\end{tabular}

From table (4) comparison between the three groups for candidal colonies, showed statistically highly significant difference between GII and GIII in favor to acrifast denture base $(\mathrm{p}=0.001)$, also highly significant difference between GI and G II in favor to heat cured denture base $(\mathrm{p}=0.009)$ and finally there was no significant difference between G I and G III ( $\mathrm{p}=0.135)$.

Table (4) Comparison between the three groups for palatal denture bases adaptation.

\begin{tabular}{|l|l|l|l|}
\hline Comparison & D & LSD & p-value \\
\hline $\begin{array}{l}\text { Microwave cured denture base } \\
\text { and acrifast denture base }\end{array}$ & 66.5 & 31.275 & $0.001^{* *}$ \\
\hline $\begin{array}{l}\text { Microwave cured denture base } \\
\text { and heat cured denture base }\end{array}$ & 43 & 31.275 & $0.009 * *$ \\
\hline $\begin{array}{l}\text { Heat cured denture base and } \\
\text { acrifast denture base }\end{array}$ & 23.5 & 31.275 & 0.135 \\
\hline
\end{tabular}

\section{DISCUSSION}

Thirty identical maxillary denture bases with uniform thickness were constructed to reproduce the same denture base contours. This standardization offers a simulated denture base with minimized variation in polymerization changes that might be attributed to the influence of size of specimens, also to ensure uniformity and permit comparisons ${ }^{12}$. 
Heat cured acrylic resin was considered as the control group as it is one of the most common method of curing since many years in the field of dentistry. Processing with long cycle at $74{ }^{\circ} \mathrm{c}$ for 8 hours without terminal boil to provide slow rate of polymerization which affects monomer vaporization which might affect the accuracy in palatal denture base adaptation, potential porosity and harboring of candidal colonization. ${ }^{13}$

Microwave technique has the advantage of decreased the time needed for laboratory procedures as microwave energy acts on the monomer promoting uniform and immediate heating of the polymer mass it is also considered as a cleaner method of processing.$^{8}$

Thermal processing with injection system includes controlled curing procedure as PMMA resin is continuously injected at pressure to overcome polymerization shrinkage. ${ }^{14}$

Electronic digital caliper capable of registering minute changes that occurred in the distance between fitting palatal surface of maxillary denture bases and maxillary casts after processing, it is easy to read and can be zeroed at any point, also its tips can be applied to fit across the points to be measured. ${ }^{15}$

Irregular fitting surface can increased the probability of harboring fungi as it is including incisive papilla and a part of rugae area which simulate the tissue topography that is irregular. ${ }^{\mathbf{1 6}}$

The control medium was prepared from sabouraud 's broth without candidal inoculation because of denture bases had some artifacts which lead to interruption in counting candaidal colonies ,so that control medium was prepared to identify the shape of this artifacts that leading to distinguish between the candidal colonies and these artifacts became more accurate ${ }^{17}$

This study showed change in palatal denture base adaptation after processing by the three groups.
For Group (I) and G(II) might be attributed to combination of factors such as intrinsic features of the material , the monomer/ polymer ratio , thermal expansion and contraction during cooling, stresses elevated during removal of the flask from hydraulic press and presence of porosity. All these reasons lead to decrease palatal adaptation of denture base. ${ }^{18}$

The highest mean value of palatal denture base adaptation was observed in (G III) this might be due to; the curing was automatically controlled by the injecting unit resulting in accuracy in pressure, temperature and injecting time leading to compact dentures with good compatibility. ${ }^{6}$

Delivering the resin in a cartridge found in granular form so there was no manipulation errors leading to increased palatal denture base adaptation .The pressure is automatically kept constants for one minute after material injection so that setting contraction is compensated ${ }^{7}$

Also this study showed different degrees of candidal colonization for the three groups. This might be attributed to presence of irregularities, residual monomer, porosity that produce rough surface texture leading to retention of candida albicans. This result was in agreement with a study which reported that specimens prepared by long cycle water bath polymerization had less candidal colonization due to better surface texture and less porosity than microwave - cured specimens ${ }^{19}$

The lowest mean value of candidal colonization was observed in (GIII) . This might be due to the processing by the injection molding technique which produces material with good properties ( like little polymerization shrinkage) also it doesn't have monomer so there is less porosity, have perfect adaptation, have' better surface texture and least candidal colonization. ${ }^{20}$ 


\section{CONCLUSION}

Based on the results of this study, it can be concluded that:

Injectable monomer free thermoplastic resin denture base material is preferred to minimize candidal colonization and enhancing the accuracy of denture base adaptation and increasing the opportunity for obtaining successful complete denture.

\section{REFERENCES}

1- Rajul V, Romesh S .Denture base Materials: Some relevant properties and their determination. Int J Dent Oral Health. 2015; 1. 1-3.

2- Sharaz S , Harleen S. Effect of Reinforcement Using Stainless Steel Mesh and Glass Fibers on the Impact Strength of Heat Cure Denture Base Resin. J Int Oral Health. 2015; 7: 71-79.

3- Khindria SK, Mittal S, Sukhija U. Evolution of denture base materials. J Ind Prosth Soc.2009; 9: 64-69.

4- Tandon R, Gupta S , Agarwal S . Denture base materials from past to future. Indian J Dent Sci. 2010;2:33-39.

5- Al-Dharrab A, Shinawi L. Thermo gravimetric Characterization of the Micro-structure Composition of Polyamide Injection Molded Denture Base Material versus Conventional Compression Molded Heat-cured Denture Base Material. J Contemp Dent Pract. 2016 1;17:99-104.

6- Ardelean L, Bortun C, Motoc M. Metal-free removable partial dentures made of a thermoplastic acetal resin and two polyamide resins. Materiale Plastice. 2007; 44: 345-348

7- Singh JP, Dhiman RK, Bedi RP, Girish SH. Flexible denture base material a viable alternative to conventional acrylic denture base material. Contemp Clin Dent.2011;2:313-317.

8- Rizzatti-Barbosa, Ribeiro da Silva. Influence of Double Flask Investing and Microwave Heating on the Superficial Porosity, Surface Roughness, and Knoop Hardness of Acrylic Resin. J Prosthodont. 2009; 18: 503-506.

9- Pereira-Cenci T, Del Bel Cury AA, Crielaard W, Ten
Cate JM. Development of candida - associated denture stomatitis. J Appl Oral Sci. 2008 ; 16 : 86-94.

10- Hemal A, Rupal S, Neha A. The adherence of Candida albicans on surface of different denture base materials. Ind J Bas . 2013;2: 576-581.

11- Rajani K, Harikesh R, Sunil MV. Surface adherence of Candida albicans to different polymethyle methacrylate denture base resins. Int J Prosth.2011;2: 2-7 .

12- Leonardo R , Ferraz M .Effect of packing type on the dimensional accuracy of denture base resin cured by the conventional cycle in relation to post - pressing time. Braz Dent J.2004;15:63-67.

13- Phillips R W, Anusavice K J,. Denture base resins. Phillip's science of dental material. ch. 22:721-756.11 th ed. 2003. W.B. Saunders Company; St. Louis, Missouri.

14- Negrutiu M ,Rominu M, Pop D , Lakatos S. Thermoplastic resins for flexible framework removable partial dentures. Timisoara Medical Journal.2005;55: 295-299.

15- Jackson A, Lang B, Wang R. The influence of teeth on denture base processing accuracy. Int J Prosth. 1993;6:333-340.

16- Nalbant A, Kalkanci A, Filiz B, Kustimur S. Effectiveness of different cleaning agents against the colonization of Candida and the in Vitro detection of the adherence of these yeast cells to denture acrylic surfaces. Yonsei Med J. 2008;49:647-654.

17- Zahraa Nazar Al-Wahab. Adhesion of Candida Albicans to Denture Base and Denture Liners with Different Surface Roughness An In-vitro Study. Smile Dental Journal. 2001;4:47-54.

18- Correr-Sobrinho L .Influence of storage period and effect of different brands of acrylic resin on the dimensional accuracy of the maxillary denture base .Braz Dent $\mathrm{J}$. 2008;4:6-9.

19- Sang E, Park D, Ryan B, Srinivas M. Candida albicans adherence to surface-modified denture resin surfaces .J Prosth. $2008 ; 17: 365-369$.

20- Kang SH, Hong SH, Kim KH and Kwon TY. Influence of surface characteristics on the adhesion of Candida albicans to various denture lining materials. ActaOdontol Scand. $2013 ; 71: 241-248$ 